\title{
Influence of Cement Thickness on Adhesive Properties of CAD/CAM Fabricated One-piece Fiber Post-and-core: Micro Push-out and Finite Element Analysis Study
}

\author{
Jing Su${ }^{1}$, Qing Cai ${ }^{1^{*}}$, Zhixin Huang ${ }^{2}$, Hongcheng Zhang ${ }^{1}$, Xuliang Deng $^{3^{*}}$ and Xiaoping Yang ${ }^{1}$ \\ ${ }^{1}$ State Key Laboratory of Organic-Inorganic Composites, Beijing University of Chemical Technology, P.R. China \\ ${ }^{2}$ Pera Corporation Limited, Beijing, P.R. China \\ ${ }^{3}$ Department of Geriatric Dentistry, Peking University School and Hospital of Stomatology, Beijing 100081, P.R. China
}

${ }^{*}$ Corresponding authors: Qing Cai, State Key Laboratory of Organic-Inorganic Composites, Beijing University of Chemical Technology, P.R. China, Tel: +86 10 64412084; Fax: +86-10-64412084; E-mail: caiqing@mail.buct.edu.cn

Xuliang Deng, Department of Geriatric Dentistry, Peking University School and Hospital of Stomatology, Beijing 100081, P.R. China, Tel: +86 10 82195637; Fax: +86 10 82195581; E-mail: kqdengxuliang@bjmu.edu.cn

Rec date: May 26, 2016; Acc date: June 03, 2016; Pub date: June 10, 2016

Copyright: (c) $2016 \mathrm{Su} \mathrm{J}$, et al. This is an open-access article distributed under the terms of the Creative Commons Attribution License, which permits unrestricted use, distribution, and reproduction in any medium, provided the original author and source are credited.

\begin{abstract}
This study is to test if the bond strength between fiber post and dentin is inversely relative to the thickness of adhesive cement, basing on a kind of CAD/CAM fabricated one-piece fiber post-and-core (OPFPC), which was designed for individual-based endodontical treatment.

Twenty-seven noncarious single-canal extracted human teeth were endodontically treated, with the crown being removed perpendicular to the tooth long axis. OPFPC specimens with different designs in the diameter of the post were fabricated with the aid of CAD/CAM and fitted into corresponding root canals, accordingly, cement thicknesses between the post and the dentin were set as $\sim 300, \sim 150$ and $\sim 10 \mu \mathrm{m}$, respectively. Samples were prepared by sectioning the OPFPC-fitted tooth perpendicularly to tooth long axis, and subsequently submitted to micro push-out test. By using Finite Element Analysis (FEA), the Contact Press Stress (CPS) and Maximum Principal Stress (MPS) in the OPFPC-fitted tooth with different cement thicknesses were calculated.

The micro push-out test proved that the bond strength between fiber post and dentin increased apparently as the cement thickness decreasing. A common failure mode found in the test was the damage occurring at the AdhesiveDentin (AD) interface, but the Adhesive-Post (AP) interfacial failure mode was likely to be observed when the cement was relatively thick. FEA modelling indicated that interfacial stress deriving from CPS on both AD and AP interfaces increased along with thicker adhesive layer, and the MPS distribution area was reduced on both the interfaces when the cement thickness was increased. All the data suggested that better bond condition was confirmed at the thinner adhesive layer between the fiber post and the dentin. CAD/CAM fabricated OPFPC, which could fit the root canal perfect, thus demonstrated advantages over the conventional fiber post for clinical endodontical therapy.
\end{abstract}

Keywords CAD/CAM; One-piece fiber post-and-core; Cement thickness; Bond strength; Finite element analysis

\section{Introduction}

In the cases of extensively damaged teeth, the traditional restoration requires a post to be placed into the root canal, which is able to provide support for the coronal part. Fiber posts, displaying the advantage of having elasticity modulus similar to that of dentin, have been widely used in endodontic treatment to reduce the risk of tooth fracture [1]. If the diameter of the prefabricated fiber post differs much from that of root canal, however, a close fit cannot be achieved between the post and the dentin, and thus a thick layer of cement will be created between them [2].

In post-restored teeth, the main failure mode is loss of retention $[3,4]$. The cement section has been identified as a zone of highly concentrated load and stress, which is suggested to be the main reason responsible for the post debonding and dislodgement. Shrinkage stress generated from the polymerization of resin cement can cause gaps between the post and the dentin [5]. Increase in cement thickness might further enhance the post debonding, because the shrinkage extent is strongly relating to the volume of the restoration [6]. Grandini et al. proposed that polymerization stress developed in a relatively thin film of cement was minimal according to their observations on defects within resin cements of different thickness [7]. But some researchers believed that a thicker cement section could provide a relatively flexible, stress-absorbing layer between the composite restoration and the dentin substrate, which led to lower interfacial stress [8-10]. Centering on this controversial issue, numerous studies on correlating the thickness of adhesive layer with the bond strength between the post and the dentin have been reported [6-10].

To achieve long-term success in endodontic treatment with fiber post, therefore, the primary necessary is to establish a quantitative understanding on how cement thickness will influence the adhesive property of fiber post. To this end, herein, a kind of One-Piece Fiber 
Post-And-Core (OPFPC) was applied to perform the experiment. Different from conventional fiber posts, in this study, the OPFPCs were fabricated by CAD/CAM technology basing on extracted teeth and able to fit the corresponding root canal perfect. In other words, the OPFPCs were fabricated individually to resemble both the canal shape and size of each tooth, displaying excellent adaptation to the root canal without the need of standardizing root canal preparation [11]. With such an advantage feature, it was ideal to use the OPFPC for the present study because the adjustments in cement thickness were easier, more feasible and reliable than those conventional fiber posts.

The present study was carried out by using both micro push-out test and Finite Element Analysis (FEA). Micro push-out is very efficient in determining the bond strength between fiber post and root canal wall by testing fiber post-loaded tooth slices $[12,13]$. FEA is usually applied to illustrate and predict mechanical behaviors by calculating the Maximum Principle Stress (MPS), which is quite helpful in understanding practical experimental data [14-16]. In addition, a new FEA contact analysis technology was employed in this study to estimate the Contact Press Stress (CPS) at interfaces, since debonding always takes place at the adhesive interface $[2,14,17]$. The calculation on CPS was theoretically able to illustrate the acting direction of the stress [5]. Finally, the experimental data and the calculations were correlated. The null hypothesis of this study was that the change in cement thickness had no significant effect on bond strength between the OPFPC and the dentin.

\section{Materials and Methods}

\section{Tooth preparation}

Twenty-seven noncarious human teeth with single straight root were extracted from patients for periodontal and/or prosthetic reasons from Peking University School and Hospital of Stomatology (China). Soft tissue remnants on root surfaces were removed manually, subsequently, the teeth were stored in cold distilled water $\left(4^{\circ} \mathrm{C}\right)$ for 2 weeks. After that, crowns were removed from teeth perpendicularly to the tooth long axis at the place $2-\mathrm{mm}$ above the cemento-enamel junction with a high-speed diamond rotary cutting instrument (DiaBurs, TR-13EF; Mani, Inc) under water cooling. Then the teeth were mechanically cleaned with endodontic files to remove the dental pulp. The root canals were scoured with $2.5 \%$ sodium hypochlorite and dried with paper point. All the prepared root canals were then sealed with gutta-percha and AH-Plus (Densply, Germany), followed by being immersed in distilled water at $37^{\circ} \mathrm{C}$ for 7 days. Next, four types of drills (Peeso Reamers; Mani, Inc, Utsunomiya, Japan) with different diameters were used to remove the gutta-percha from the root canals, and to expand the inner spaces of root canals for the fiber post and adhesive filling in the next step. Noticeably, in this study, at least $2 \mathrm{~mm}$ of intact gutta-percha was left in the canal to preserve the apical seal. The prepared root canals were then flushed with distilled water to remove any possible debris generated during the drilling, and ready for use.

\section{Fabrication of One-Piece Fiber Post-and-Core (OPFPC)}

Referring to our previous work [11], as illustrated in Figure 1, CAD reverse design technology was used to prepare the customized OPFPC. Briefly, wax patterns (Casting Wax Bar; Shanghai Medical Instruments Co, Ltd, China) resembling the root canals were made for all the prepared teeth, and scanned with a 3D scanner (Activity 102, Smartoptics, Germany). The obtained 3D digital models were disposed by using CAD software (Pro/ENGINEER, USA) one by one, and a series of cross-sectioned curves were made on each of the digital model by using the remodeling module of Pro/ENGINEER. To control the cement thickness, the middle part of the cross-sectioned curves was offset with some specific values. Then, these offset curves were connected with those non-offset curves, and lofting surfaces were generated. Two offsetting surfaces were made with offsetting values of $300 \mu \mathrm{m}$ and $150 \mu \mathrm{m}$, and termed as G300 and G150 groups, respectively. The group with no offsetting was termed as G0 group.

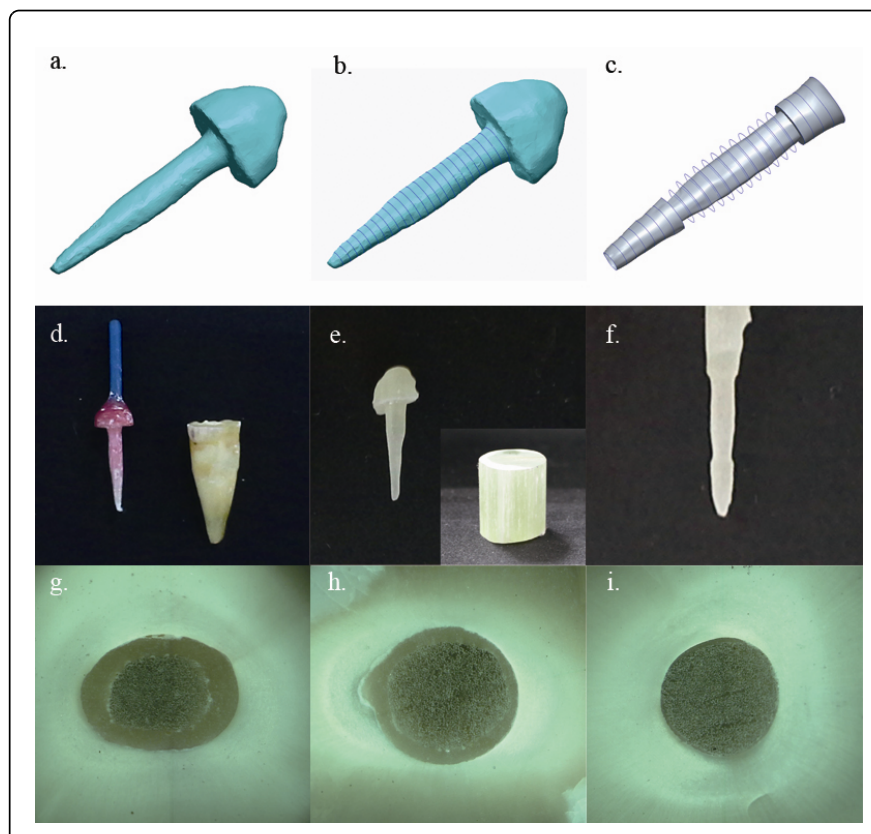

Figure 1: The process of CAD/CAM fabricated one piece fiber post and core with offsetting surface: (a) 3D digital model of wax pattern; (b) 3D CAD model generation: cross-section curves; (c) 3D CAD model generation: lofting surface; (d) wax pattern and prepared root; (e) OPFPC and glass fiber reinforced resin block; (f) fiber post with offsetting surface prepared; (g-i) stereomicroscope photos of G300 (g), G150 (h) and G0 group (i), respectively.

Accordingly, the aforementioned 27 teeth were divided into three groups, i.e., in relating to the OPFRCs used for G0, G150 or G300 group. OPFPCs were then processed basing on those 3D digital models and fitted into corresponding root canals with controllable cement thickness. Those glass fiber reinforced epoxy composite blocks were obtained from Oya Ruikang New Material Science and Technology Co., Ltd. (Beijing, China), and machined into pre-designed OPFRCs using the 5-axis Computer Numerical Control (CNC) machine tools (CAM 4-02 Impression, VHF, Germany) by importing model files in *.stl format from the CAD software.

\section{Set-up of micro push-out test}

The set-up of experimental device for micro push-out test is shown in Figure 2, together with the diagram of preparing specimens for the test.

In preparing the specimens for the push-out test, the teeth with root canal prepared were flushed with 17\% EDTA and 2.5\% sodium hypochlorite sequentially, and dried with paper points. Then a predesigned and CAD/CAM fabricated OPFPC was cemented into the root canal by using ParaCore dual-curing resin cement (Switzerland) 
according to the manufacturer's instructions. After the cement was polymerized for $40 \mathrm{~s}$ by being irradiated from the occlusal direction with a LED curing light $\left(300 \mathrm{~mW} / \mathrm{mm}^{2}\right.$, Coltolux, Switzerland $)$, the entity was preserved in distilled water at $37^{\circ} \mathrm{C}$ for 7 days. Four to six slices in the thickness of $\sim 1 \mathrm{~mm}$, being perpendicular to the long axis of the tooth, were able to be sectioned from one tooth by using a precision microtome (Isomet 1000, Buehler; Lake Bluff, IL, USA) under water cooling. The obtained slices were observed using a stereomicroscope and their typical morphology were shown in Figure 1.
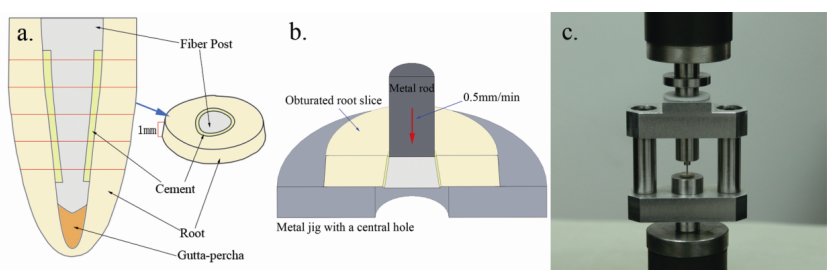

Figure 2: The micro push-out diagram: (a) specimen preparation, (b) diagram of micro push-out test and (c) the photo of the experimental device.

Clearly, the cement thickness of the sample in different groups was different as expected. To avoid large deviations in micro push-out test, those specimens showing bubbles or residual gutta-percha in cement layer were not included in the test. The actual thickness of each slice was measured using a digital caliper with an accuracy of $0.01 \mathrm{~mm}$. The thickness of the cement and the diameter of the post in each slice were measured using a custom-adapted stereomicroscope (Olympus SZX16, Japan). Because the cross-sections of all the slices displayed an elliptical shape, the cement thicknesses were calculated by averaging the measurements from two perpendicular directions.

Subsequently, the slices were submitted to the push-out test by using a Universal Material Machine (Instron 1121; Norwood, MA, USA). As illustrated in Figure 2, the specimens were put on a metal jig having a central hole, and pushed at a rate of $0.5 \mathrm{~mm} / \mathrm{min}$. The slices were placed with their coronal sides downwards, thus, the pushing was ensured from the direction of root apical to coronal. By doing so, it was able to avoid any limitation on the post movement, which might be caused by the root canal taper [13].

Three metal jigs with different dimensions in the central hole (1.5, 2.0 and $3.0 \mathrm{~mm}$ in diameter) were applied to ensure a proper support for every root slice, i.e., the central hole should be a little larger than the cement circle to avoid possible interfere in performing the push. For similar considerations, accordingly, push-out rods with proper diameters $(0.8,1.0,1.2,1.6$ and $2.0 \mathrm{~mm})$ were selected and positioned to only touch the post place without causing any stress on the surrounding cement and the root canal wall. The maximum force was recorded in Newton $(\mathrm{N})$ at the point of failure occurring, and the bond strength was calculated in MPa via dividing the applied load by the bonded area.

Because of the elliptic canal shape, the bonded area was calculated according to following equations. The elliptic perimeter $\left(l_{1}\right)$ of the section including the post and the cement on the apical face was calculated by Equation (1):

$$
l_{2}=4 a \int_{0}^{\frac{\pi}{2}} \sqrt{1-e^{2} \sin ^{2} \theta} d \theta
$$

where e is the eccentricity ratio of the ellipse, which equals to

$\sqrt{1-\left(\frac{b}{a}\right)^{2}}$, in which, $a$ and $b$ are the long axis and the short axis of the elliptic section including the post and the cement, respectively. The corresponding elliptic perimeter (12) of the coronal side was calculated similarly. Then, the bonded area (A) of the cement could be calculated by Equation (2): $\mathrm{A}=\left(l_{1}+l_{2}\right) \times h \div 2$

where $h$ is the thickness of the sliced section.

\section{Finite Element Analysis (FEA)}

In relating to practically measured cement thicknesses, three dimensional solid models with different designs in the cement thickness were generated by Pro/ENGINEER. The mechanical modeling was performed by importing the solid model into ANSYS Workbench v15 FEA software (Ansys Inc., Houston, USA) (Figure 3).

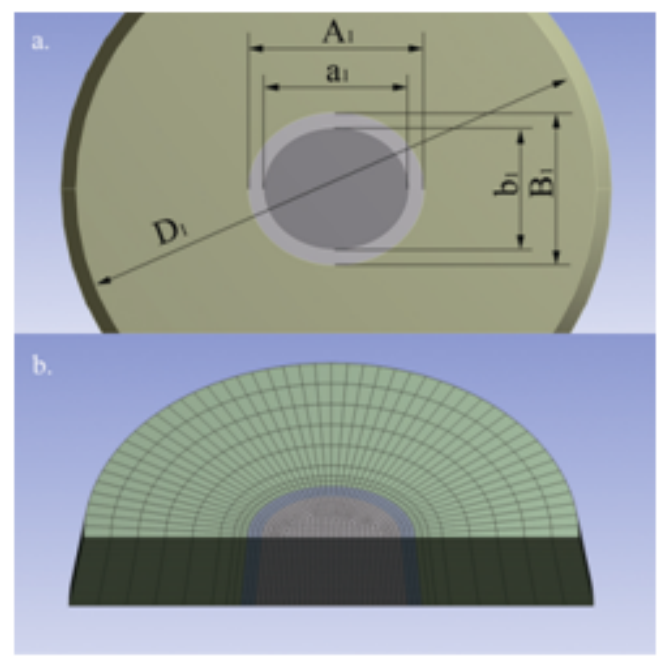

Figure 3: Geometry and mesh representations for the FEA models of dentin: (a) definitions of a1, b1, A1, B1 and D1 are shown on one side of the slice specimen. There are similar definitions of a2, b2, A2, B2 and D2 on the other side of the slice specimen, since the specimen is slightly tilting along height direction. The cement thickness is calculated by averaging all these values in G300, G150 or G0 groups. (b) The mesh size for cement and post is 20 and 100 $\mu \mathrm{m}$, respectively; using default size for root part.

Due to the geometric symmetry of the specimens, only half-profile models were created in order to limit the number of elements in the following calculation. In these models, the nodes in the centric plane were only allowed for frictionless sliding. Then the solid model was meshed with 3D 20-node hexahedral element, with three degrees of freedom at each node. Bonding contact was set on two interfaces, i.e. the Adhesive-to-Post (AP) and Adhesive-to-Dentin (AD), by being meshed with 3D 8-node surf-to-surf contact element. It was reported that stress would increase infinitely at the free edge area of adhesive joint in finite element calculations if mesh refinement was increased, 
which was called the size-dependent stress singularity $[18,19]$. To avoid this problem in our study, uniform sizes were applied to mesh all the models of cement layer, post and the root at places adjacent to the adhesive (Figure 3).

The mechanical properties of all the relating materials that were required for FEA calculation are listed in Table 1. The mechanical data of fiber post, dentin and ParaCore resin cement were assigned according to literature data [20]. The volume shrinkage ratio of ParaCore was measured by using a video-imaging device (AcuVol, Bisco, Schaum-burg, IL, USA). To assess the influence of shrinkage stress on bond strength, a linear shrinkage was simulated on cement layer via setting a thermal shrinkage ratio on its material mode with temperature boundary conditions to produce a thermal shrinkage. The linear shrinkage ratio is one third of the volume shrinkage ratio, and was applied perpendicularly to the axis of root canal in FEA calculation. The displacement in the vertical direction of dental bottom nodes was restricted. The dentin thickness was set as $5 \mathrm{~mm}$ since it was reported wall thickness having insignificant effect on shrinkage stress [21].

\begin{tabular}{|l|l|l|l|l|}
\hline \multicolumn{2}{|l|}{ Materials } & $\begin{array}{l}\text { Elastic } \\
\text { modulus (MPa) }\end{array}$ & Poisson's ratio & $\begin{array}{l}\text { Volume } \\
\text { shrinkage ratio }\end{array}$ \\
\hline \multirow{2}{*}{ Fiber post } & X axis & 9500 & 0.27 & - \\
\cline { 2 - 5 } & Y axis & 9500 & 0.27 & - \\
\cline { 2 - 5 } & Z axis & 37000 & 0.34 & - \\
\hline Cement & 17000 & 0.23 & 0.0509 \\
\hline Dentin & 18600 & 0.31 & - \\
\hline
\end{tabular}

Table 1: Material properties used in the FEA models.

To evaluate the magnitude of the shrinkage stress in different groups, CPSs on both AD and AP interfaces were calculated because CPS could reflect the stress state perpendicularly to these interfaces. Meanwhile, MPSs on both AD and AP interfaces were also calculated and used to analyze the fracture mode in groups with different cement thickness.

\section{Statistical analysis}

All the calculations on bonded areas and relating statistical analysis were performed using MATLAB software (The MathWorks, Inc., Massachusetts, Natick, USA). Both one-way ANOVA and linear regression analysis were applied to access the influence of cement thickness on bond strength, and the correlation was tested using Tukey test $(\mathrm{p}<0.05)$ and F-check method $(\mathrm{p}<0.05)$, respectively.

\section{Results}

\section{Micro push-out test}

The cement thickness in each of the prepared slices was measured precisely before they were submitted to the micro push-out test. Although the deviation of the 3D digital model of each OPFRC were set as 300,150 or $0 \mu \mathrm{m}$, the actual cement thickness measured from different slices demonstrated fluctuations. As shown in Table 2, the average cement thickness in the G300 group was $306.0 \pm 67.7 \mu \mathrm{m}$, and the average value in the G150 group was $144.9 \pm 24.9 \mu \mathrm{m}$. As for the G0 group, the cement thickness was found $65.5 \pm 23.0 \mu \mathrm{m}$, which was practically required for the fixation of OPFRC into the root canal.

\begin{tabular}{|l|l|l|l|l|l|l|}
\hline \multirow{2}{*}{ Group } & $\begin{array}{l}\text { Mean } \\
\text { Cement } \\
\text { Thickness } \\
(\boldsymbol{\mu})\end{array}$ & $\begin{array}{l}\text { Fracture } \\
\text { Strength } \\
(\mathrm{MPa})\end{array}$ & \multicolumn{3}{|l|}{ Fracture Mode } & \multicolumn{2}{|l|}{$\begin{array}{l}\text { Specimen } \\
\text { Number }\end{array}$} \\
\cline { 4 - 7 } & AP & AD & Mixed & \\
\hline G300 & $306.0(67.7)$ & $5.66(3.30)$ & 7 & 20 & 1 & 28 \\
\hline G150 & $144.9(24.9)$ & $8.62(3.60)$ & 1 & 17 & 14 & 32 \\
\hline G0 & $65.5(23.0)$ & $9.56(3.70)$ & 2 & 20 & 7 & 29 \\
\hline
\end{tabular}

Table 2: Cement thickness, fracture strength, fracture mode and total specimen number for each group for micro push-out test.

In each group, about 30 specimens were conducted the push-out test. The obtained fracture strengths are presented in Table 2, and were analyzed using one-way ANOVA. The fracture strength displayed a clear increasing trend along with the cement thickness becoming thinner. The bond strength obtained in the G300 group demonstrated significant difference from the other two groups $(\mathrm{p}<0.05)$, while no significant difference was found between the G150 group and the G0 group.

Failure modes for all the pushed out slices were evaluated, classified and counted. Three kinds of fracture mode were detected, i.e., fracture occurring only at the AP interface (AP mode), only at the AD interface ( $\mathrm{AD}$ mode), or at both the $\mathrm{AP}$ and $\mathrm{AD}$ interfaces simultaneously together with cement cracking (Mixed mode). It was found that the $\mathrm{AD}$ mode was the dominant failure mode in all the three groups. In the case of G300 group, however, the AP mode was more liable to occur in comparison with the other two groups. Besides, the mixed mode was found in a higher probability in the G150 group than in the G0 group. These data suggested that fracture likely took place at the AP interface when the cement thickness was increased.

To correlate the cement thickness with the fracture strength, linear regression analysis was calculated and the results are presented in Figure 4. Those data from the AP fracture mode were not included in the linear regression analysis because the stress state at the AP interface was different from that at $\mathrm{AD}$ the interface. As shown in Figure 4, a negative slope was identified, which displayed bond strengths being negatively correlating to cement thicknesses. The analysis suggested that an increase in bond strength could be expected by reducing the cement thickness.

\section{Finite Element Analysis (FEA)}

Both the CPS values and distributions were calculated by using FEA in relating to $A D$ and $A P$ interfaces for the three groups of G300, G150 and G0. The calculation results are illustrated in Figure 5. From the figure, negative CPS values were obtained on all the AD interfaces, while positive CPS values were identified on all the AP interfaces. Those negative values indicated that it was the tensile stress acting at the $\mathrm{AD}$ interface, while those positive values revealed the presence of compressive stress at the AP interface owing to the polymerization shrinkage of the cement. Nevertheless, whether being negative or positive, the absolute values of these CPS decreased gradually along with thinner cement thickness. Within the same group, the tensile stress on the $\mathrm{AD}$ interface was found significantly higher than the compressive stress value on the corresponding AP interface. Theoretically, higher tensile stress on the interface would result in higher probability in causing failure during the micro push-out test. 


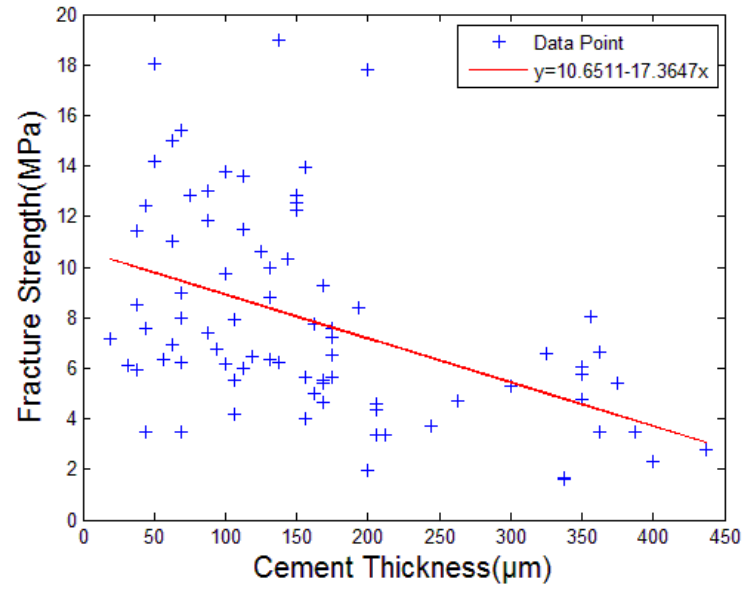

Figure 4: Linear regression to correlate fracture strength with cement thickness. The chart represents regression, $95 \%$ confidence intervals and linear equations. R2 $=0.2118$.

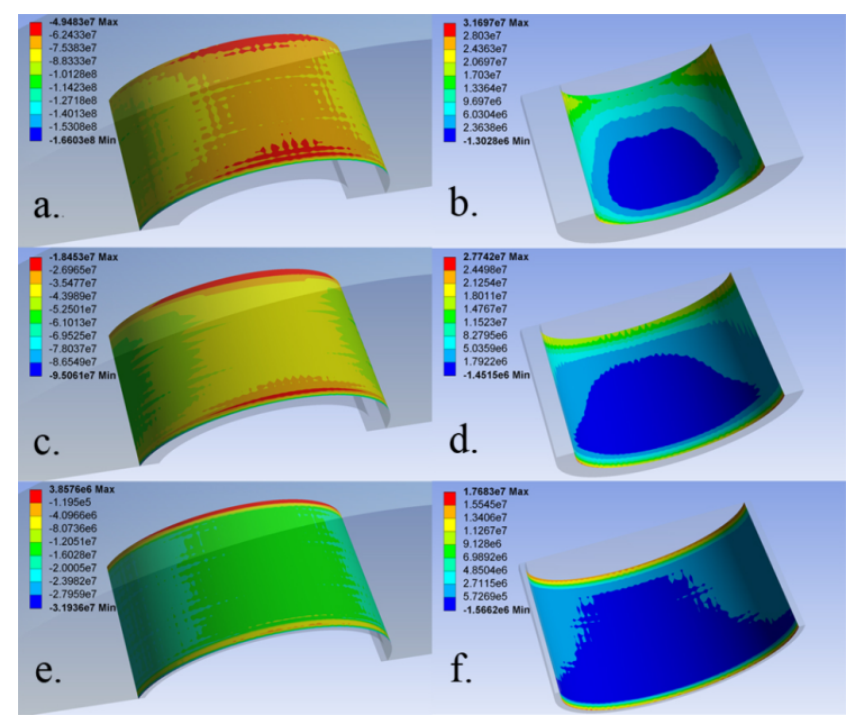

Figure 5: FEA calculated CPS status at both the AD (left column) and the AP (right column) interfaces for groups of $\mathrm{G} 300(\mathrm{a}, \mathrm{b})$, $\mathrm{G} 150(\mathrm{c}, \mathrm{d})$ and $\mathrm{G} 0(\mathrm{e}, \mathrm{f})$.

MPS values on both the $\mathrm{AD}$ and the AP interfaces were also evaluated by using FEA, and the results are displayed in Figure 6. When the cement thickness was reduced, as shown in the figure, increases in the MPS values on the AD interface were identified in the order of $\mathrm{G0}>\mathrm{G} 150>\mathrm{G} 300$, while decreases in the MPS values were identified on the AP interface in the order of G0 $<$ G150<G300. Within the same group, the maximum MPS value was found significantly higher on the AP interface than that on the corresponding $\mathrm{AD}$ interface. However, the difference between the two maximum MPS values became smaller when the cement thickness turned thinner. Besides, the area of the MPS distribution on both the AD and the AP interfaces were observed expanding gradually when the cement thickness was thinner.

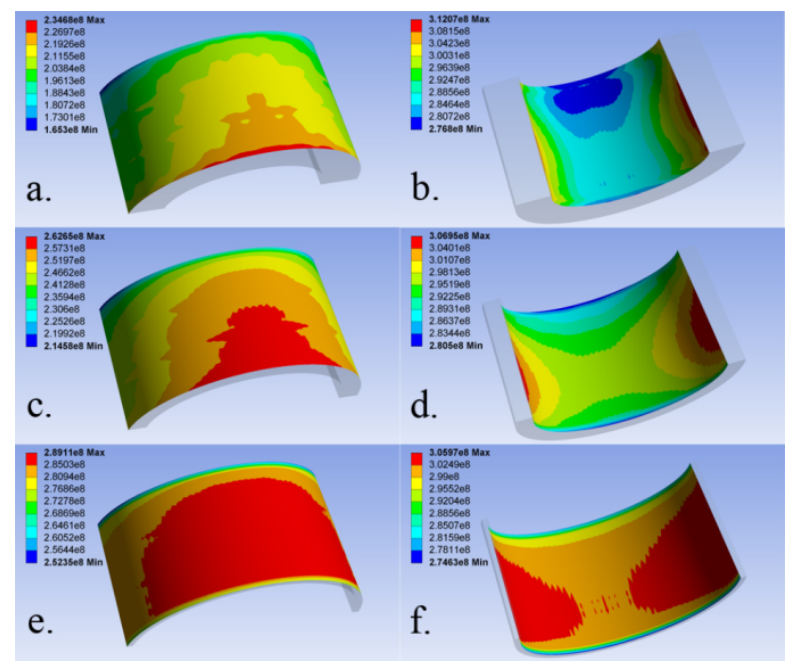

Figure 6: FEA calculated MPS at both the AD (left column) and the AP (right column) interfaces for groups of G300 (a, b), G150 (c, d) and $\mathrm{GO}(\mathrm{e}, \mathrm{f})$.

\section{Discussion}

In endodontic treatment, polymeric adhesive cement was normally applied in fixing fiber posts into root canal. Although the CAD/CAM produced OPFPC could fit the shape of root canal much more perfect than conventional fiber posts, there were still uncertainties in controlling the thickness of the cement. From clinical trials, many dentists believed that the adhesive layer should be as thin as possible to achieve a strong bonding between the dentin and the post. A main concern about the thick adhesive layer was worrying about its high polymerization shrinkage, which might cause high compressive stress on the fiber post and cause adverse effect on bond strength [22,23]. But some researchers stated that a thick cement layer was able to provide a relatively flexible, stress-absorbing layer between the restoration material and the dentin, thus, resulting in a low interfacial stress $[8,24]$. In viewing of these uncertainties, herein, different cement thicknesses were designed and practiced by using a kind of individually-fabricated OPFRC with the aid of CAD/CAM for the purpose to correlate the bond strength with the cement thickness. At the same time, the guidance for machining OPFRC in clinical treatment was able to be obtained from this study.

Many researches had found that bond strength between the post and the dentin would decrease along with the depth of root canal increasing, because it was harder for the curing light to reach a deeper part of the root canal [1,25-29]. To avoid this variation, in this study, only those slices from the middle part of the root canal were used for the micro push-out test. Besides, the volume of restoration was also reported able to influence the stress generated by the polymerization shrinkage of the cement [6]. To ensure each extracted root specimen having similar volume of restoration, in this study, the different cement thickness was achieved by reducing the diameter of the post instead of expanding the root canal. As shown in Figure 1, this strategy was readily put to work by modifying the CAD model of OPFPC before CAM machining. All the slices were checked carefully under stereomicroscope to pick out specimens without visible bubbles in the cement layer for the push-out test, because the entrapped bubbles were likely to act as initial cracks to cause poor adhesion [30]. With eliminating these interferences, the decrease in the bond strength in 
the case of thicker cement layer, as shown in Table 2 and Figure 4, was suggested closely relating to its higher polymerization shrinkage stress. Polymerization shrinkage is the inherent feature of polymeric adhesives, and thicker cement layer would generate higher polymerization shrinkage stress $[4,16]$.

In Figure 5, FEA calculations on the CPS status at both the AD and the AP interfaces were provided to support the push-out results. To do the calculation, the cement thickness values used in the models were those practically measured data from Table 2. And in order to avoid the phenomenon of stress concentration at edges of bond interfaces, in the calculation, liner shrinkage ratio was applied instead of volume shrinkage ratio, which was referring to a similar setting reported by a previous publication [16]. From Figure 5, the absolute CPS values at both the $\mathrm{AD}$ and the $\mathrm{AP}$ interfaces were calculated increasing gradually along with thicker cement layer. It indicated that fracture would be more likely to occur in a thicker cement layer. This finding on our CAD/CAM fabricated OPFPC was consistent with other reports on relationship of bond strength and cement thickness by using micro push-out test or micro tensile test $[15,16,22,23,27]$.

Noticeably, the CPS at the AD interface was calculated negative, while the CPS at the AP interface was calculated positive (Figure 5). The sign of positive or negative was correlating to the direction of polymerization shrinkage stress. As the cement layer polymerized with shrinkage, apparently, compressive stress would be loaded on the post surface at the AP interface, while tensile stress would be acted on the dentin surface at the $\mathrm{AD}$ interface. Thus, it was easy to infer that debonding would more likely to take place at the $\mathrm{AD}$ interface than at the AP interface during the push-out test. As shown in Table 2, the AD fracture mode was indeed the main failure mode in all the groups.

When the cement thickness was increased, however, the ratio of the AP fracture mode was found slightly increasing. On one hand, this might be caused by the possible plastic flow during the curing of cement $[24,31]$. It was supposed that the gelation of cement occurred from the outside to the inside when it was exposed to curing light. Thus, the plastic flow of the uncured inner cement might relieve some of the tensile stress at the AD interface. Normally, the plastic flow procedure was insignificant when a deep cavity with high configuration factor (C-factor, the ratio of bonded area to unbounded area) was applied $[16,31,32]$. On the other hand, therefore, the curing degree of cement layer might responsible for the increasing AP fracture ratio when the cement was thicker. In this study, the curing light irradiated the cement layer, which might cause inefficient curing at the AP interface when the cement layer was thicker. Accordingly, all the results in relating to the AP failure mode were not included in the linear regression analysis to avoid misleading inference (Figure 4). The analysis displayed the negative dependence of bond strength to cement thickness clearly.

Finally, MPS status was also computed to analysis those failure modes listed in Table 2. As shown in Figure 6, the distribution of peaked MPS became wider as the cement layer was thinner. This simulation revealed that larger area in the thinner cement layer might suffer high internal stress, which would like to trigger a kind of cohesive fracture inside the cement. If there were some initial cracks distributing inside the cement layer, the cohesive fracture should cause the split of the cement and the Mixed fracture mode was detected in the micro push-out test. However, the data in Table 2 did not show that G0 group had a higher probability in causing the cohesive fracture than the other two groups. This result suggested that few defect such as cracks and bubbles would be generated during cement filling and curing if the cement layer was thin, which reduced the occurring probability of cohesive fracture. Accordingly, high bond strength was determined in the group of thin cement layer.

\section{Conclusion}

Using a kind of CAD/CAM produced OPFPC; the thickness of the cement layer was readily adjusted without sacrificing the restoration volume. Thinner cement layer would generate less tensile stress at the $\mathrm{AD}$ interface due to its lower polymerization shrinkage stress. And thin cement layer would have few defects to cause cohesive fracture. Therefore, thinner cement layer would lead to higher bond strength between the post and the dentin. In comparison with conventional fiber posts, promisingly, the CAD/CAM produced OPFPC illustrated excellent adaptation to root canal, and was able to achieve strong bonding properties in the canal to prevent dislodgement by minimizing the cement thickness. These features made OPFPCs especially suitable in restoring the flared roots or defected teeth with incomplete ferrule, which were hard to achieve satisfactory restorations by using conventional pre-fabricated fiber posts.

\section{Acknowledgements}

The authors acknowledged the financial supports from National Natural Science Foundation of China (No. 51373016), Beijing Municipal Commission of Education (ZDZH20141001001).

\section{References}

1. Zicari F, De Munck J, Scotti R, Naert I, Van Meerbeek B (2012) Factors affecting the cement-post interface. Dent Mater 28: 287-297.

2. Pest LB, Cavalli G, Bertani P, Gagliani M (2002) Adhesive postendodontic restorations with fiber posts: push-out tests and SEM observations. Dent Mater 18: 596-602.

3. Cagidiaco MC, Goracci C, Garcia-Godoy F, Ferrari M (2008) Clinical studies of fiber posts: a literature review. Int J Prosthodont 21: 328-336.

4. Ferrari M, Cagidiaco MC, Goracci C, Vichi A, Mason PN, et al. (2007) Long-term retrospective study of the clinical performance of fiber posts. Am J Dent 20: 287-291.

5. Kowalczyk P (2009) Influence of the shape of the layers in photo-cured dental restorations on the shrinkage stress peaks-FEM study. Dent Mater 25: e83-91.

6. Braga RR, Boaro LC, Kuroe T, Azevedo CL, Singer JM (2006) Influence of cavity dimensions and their derivatives (volume and ' $\mathrm{C}$ ' factor) on shrinkage stress development and microleakage of composite restorations. Dent Mater 22: 818-823.

7. Grandini S, Goracci C, Monticelli F, Borracchini A, Ferrari M (2005) SEM evaluation of the cement layer thickness after luting two different posts. J Adhes Dent 7: 235-240.

8. Alonso RC, Sinhoreti MA, Sobrinho LC, Consani S, Goes MF (2004) Effect of resin liners on the microleakage of class $\mathrm{V}$ dental composite restorations. J Appl Oral Sci 12: 56-61.

9. Choi KK, Condon JR, Ferracane JL (2000) The effects of adhesive thickness on polymerization contraction stress of composite. J Dent Res 79: $812-817$.

10. Silva NR, Calamia CS, Harsono M, Carvalho RM, Pegoraro LF, et al. (2006) Bond angle effects on microtensile bonds: laboratory and FEA comparison. Dent Mater 22: 314-324.

11. Liu P, Deng XL, Wang XZ (2010) Use of a CAD/CAM-fabricated glass fiber post and core to restore fractured anterior teeth: A clinical report. J Prosthet Dent 103: 330-333.

12. Erdemir U, Mumcu E, Topcu FT, Yildiz E, Yamanel K, et al. (2010) Micro push-out bond strengths of 2 fiber post types luted using different adhesive strategies. Oral Surg Oral Med Oral Pathol Oral Radiol Endod 110: 534-544.

13. Goracci C, Tavares AU, Fabianelli A, Monticelli F, Raffaelli O, et al. (2004) The adhesion between fiber posts and root canal walls: comparison 
Citation: Su J, Cai Q, Huang Z, Zhang H, Deng X, et al. (2016) Influence of Cement Thickness on Adhesive Properties of CAD/CAM Fabricated One-piece Fiber Post-and-core: Micro Push-out and Finite Element Analysis Study. Dentistry 6: 382. doi:10.4172/2161-1122.1000382

Page 7 of 7

between microtensile and push-out bond strength measurements. Eur J Oral Sci 112: 353-361.

14. Braga RR, Meira JB, Boaro LC, Xavier TA (2010) Adhesion to tooth structure: A critical review of "macro" test methods. Dent Mater 26: e38-49.

15. Coelho PG, Calamia C, Harsono M, Thompson VP, Silva NR (2008) Laboratory and FEA evaluation of dentin-to-composite bonding as a function adhesive layer thickness. Dent Mater 24: 1297-1303.

16. Jongsma LA, Ir Nde J, Kleverlaan CJ, Feilzer AJ (2011) Reduced contraction stress formation obtained by a two-step cementation procedure for fiber posts. Dent Mater 27: 670-676.

17. Gallo JR 3rd, Miller T, Xu X, Burgess JO (2002) In vitro evaluation of the retention of composite fiber and stainless steel posts. J Prosthodont 11: 25-29.

18. Campillo-Funollet M, Dargush GF, VanSlooten RA, Mollendorf JC, Kim H, et al. (2014) Size-dependent strength of dental adhesive systems. Dent Mater 30: e216-228.

19. Neves AA, Coutinho E, Poitevin A, Van der Sloten J, Van Meerbeek B, et al. (2009) Influence of joint component mechanical properties and adhesive layer thickness on stress distribution in micro-tensile bond strength specimens. Dent Mater 25: 4-12.

20. Passos SP, Freitas AP, Jumaily S, Santos MJ, Rizkalla AS, et al. (2013) Comparison of mechanical properties of five commercial dental core build-up materials. Compend Contin Educ Dent 34: 62-63, 65-8.

21. Braga RR, Koplin C, Yamamoto T, Tyler K, Ferracane JL, et al. (2013) Composite polymerization stress as a function of specimen configuration assessed by crack analysis and finite element analysis. Dent Mater 29: 1026-1033.

22. Gomes GM, Rezende EC, Gomes OM, Gomes JC, Loguercio AD, et al. (2014) Influence of the resin cement thickness on bond strength and gap formation of fiber posts bonded to root dentin. J Adhes Dent 16: 71-78.
23. Özcan E, Çetin AR, Tunçdemir AR, Ülker M (2013) The effect of luting cement thicknesses on the push-out bond strength of the fiber posts. Acta Odontol Scand 71: 703-709.

24. Kemp-Scholte CM, Davidson CL (1990) Complete marginal seal of Class $\mathrm{V}$ resin composite restorations effected by increased flexibility. J Dent Res 69: $1240-1243$

25. Aksornmuang J, Foxton RM, Nakajima M, Tagami J (2004) Microtensile bond strength of a dual-cure resin core material to glass and quartz fibre posts. J Dent 32: 443-450.

26. Aksornmuang J, Nakajima M, Foxton RM, Tagami J (2006) Regional bond strengths of a dual-cure resin core material to translucent quartz fiber post. Am J Dent 19: 51-55.

27. Mirmohammadi H, Gerges E, Salameh Z, Wesselink PR (2013) Effect of post diameter and cement thickness on bond strength of fiber posts. Quintessence Int 44: 801-810.

28. Schüpbach P, Krejci I, Lutz F (1997) Dentin bonding: effect of tubule orientation on hybrid-layer formation. Eur J Oral Sci 105: 344-352.

29. Yoshikawa T, Sano H, Burrow MF, Tagami J, Pashley DH (1999) Effects of dentin depth and cavity configuration on bond strength. J Dent Res 78: 898-905.

30. Macedo VC, Faria e Silva AL, Martins LR (2010) Effect of cement type, relining procedure, and length of cementation on pull-out bond strength of fiber posts. J Endod 36: 1543-1546.

31. Feilzer AJ, De Gee AJ, Davidson CL (1987) Setting stress in composite resin in relation to configuration of the restoration. J Dent Res 66: 1636-1639.

32. Bouillaguet S, Troesch S, Wataha JC, Krejci I, Meyer JM, et al. (2003) Microtensile bond strength between adhesive cements and root canal dentin. Dent Mater 19: 199-205. 